九州大学学術情報リポジトリ

Kyushu University Institutional Repository

Development of an Intelligent Robot for an Agricultural Production Ecosystem (VII) : Image Processing and Analysis of the Activity of Snai l in Paddy

Luna Maldonado, Alejandro Isabel

Laboratory of Agricultural Ecology, Division of Agricultural Ecology, Department of Plant Resources, Faculty of Agriculture, Kyushu University

Yamaguchi, Yusuke

Laboratory of Agricultural Ecology, Division of Agricultural Ecology, Department of Plant Resources, Faculty of Agriculture, Kyushu University

Nakaji, Ke i

Laboratory of Agricultural Ecology, Division of Agricultural Ecology, Department of Plant Resources, Faculty of Agriculture, Kyushu University

https://doi.org/10.5109/14068

出版情報: 九州大学大学院農学研究院紀要. 54 (1)，pp.247-250，2009-02-27. Faculty of Agriculture, Kyushu University

バージョン :

権利関係 : 


\title{
Development of an Intelligent Robot for an Agricultural Production Ecosystem (VII) - Image Processing and Analysis of the Activity of Snail in Paddy -
}

\author{
Yusuke YAMAGUCHI ${ }^{1}$, Alejandro Isabel LUNA MALDONADO ${ }^{1}$ \\ and Kei NAKAJI* \\ Laboratory of Agricultural Ecology, Division of Agricultural Ecology, Department of \\ Plant Resources, Faculty of Agriculture, Kyushu University, \\ Fukuoka 811-2307, Japan \\ (Received November 14, 2008 and accepted December 5, 2008)
}

\begin{abstract}
An image processing analysis was done to observe and measure the activity of snails by trough the calculating of speed of them using the AVI (Audio Video Interleave) files. The speed we obtained using the mode we constructed is highly consistent with real speed observed. This method could be useful to determine the parameters of Holling equation such as predation rate and predation coefficient of the snails to rice plants.
\end{abstract}

\section{INTRODUCTION}

The intelligent robot controls the number of golden apple snail to fit the rice production ecosystem. The understanding of the ecosystem of the paddy field is necessary to make the robot and the predator-prey model should be introduced to the robot. The speed of snails is inevitable to construct the model of predator (snail) prey (rice and weeds) using Holling equation and parameters: predation rate and predation coefficient. In this research we constructed the Simulink model to calculate the speed of the snails automatically from movie of AVI files recorded in the laboratory and paddy field.

\section{MATERIALS AND METHODS}

\section{Speed of the snails}

The travel speed of the snail was calculated using Matlab, Simulink, their toolboxes and Blocksets. A video was taken of the moving snails by a Field Server both in the laboratory (Fig. 1) and paddy field (Fig. 2). A measuring tape was attached on the wall of the bath for calculating the traveled distance of the snail.

The camera used was from a Field Server, which records three frames in jpg format per second. From those pictures the AVI files were created by using of Matlab. The Simulink model which was thought and constructed for calculating speed of snails is shown in Fig. 3. This model imported the AVI files of the snail movement in the laboratory and in the paddy field. The Subsystem block has the same blocks as are shown in Fig. 4 .

After extracting a snail in the Subsystem block such was introduced in a previous researching (Luna et al., 2009e) the Blob Analysis block and Draw Markers block were attached. Blob Analysis block calculates statistics

${ }^{1}$ Laboratory of Agricultural Ecology, Division of Agricultural Ecology, Graduate School of Bioresources and Bioenvironmental Sciences, Kyushu University

* Corresponding author (E-mail: knkjfam@mbox.nc.kyushu-u. ac.jp)

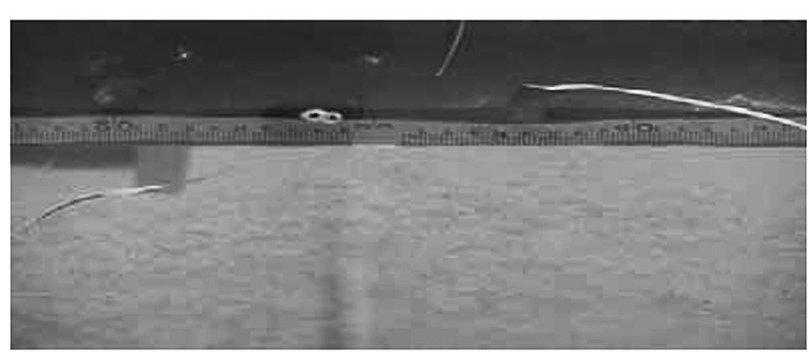

$1 / 4$

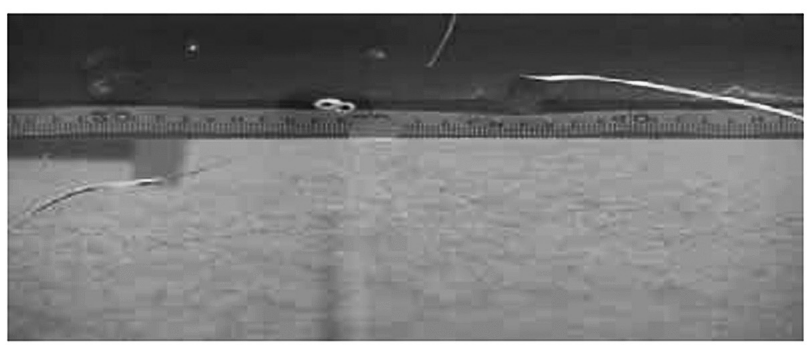

$2 / 4$

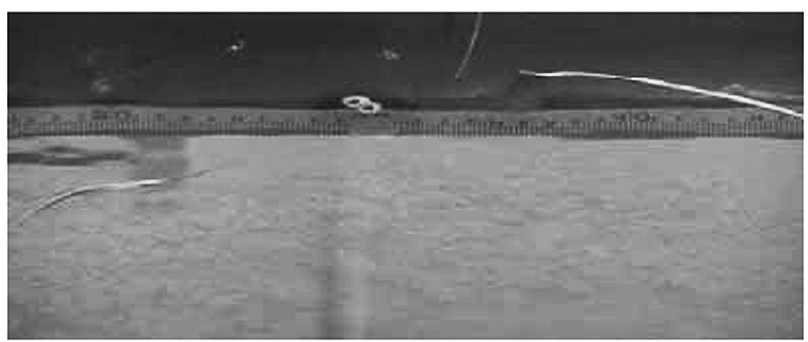

$3 / 4$

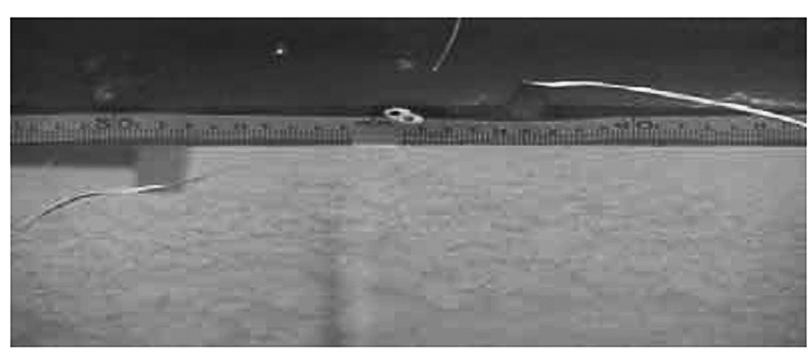

44

Fig. 1. Sequence of four frames of the movie of a snail traveling inside of the water of the bath of the laboratory for $25 \mathrm{sec}-$ onds. 


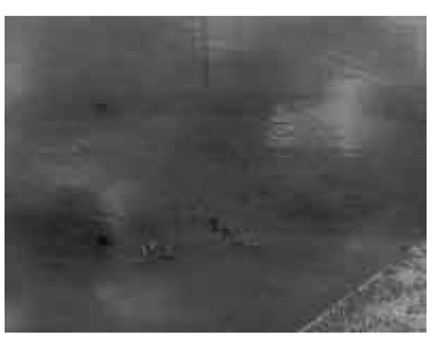

$1 / 4$

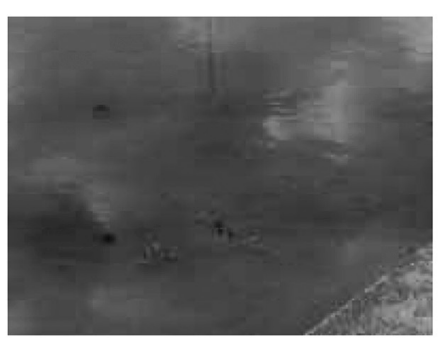

$2 / 4$

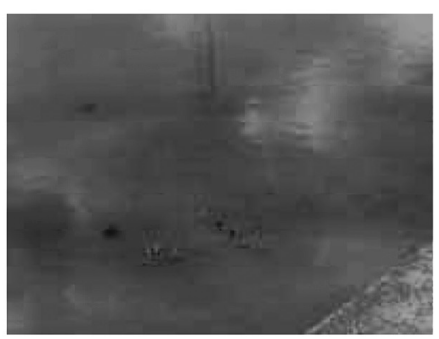

$3 / 4$

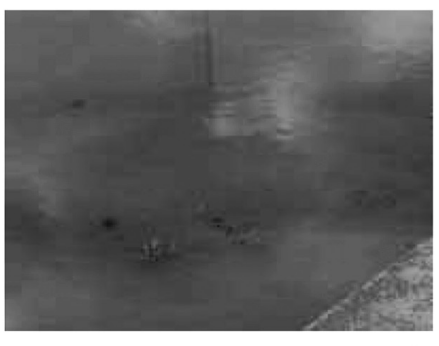

$4 / 4$

Fig. 2. Sequence of four frames of the movie of some snails moving in paddy for 19 seconds on the crop season of 2008. The speed of the upper snail in the pictures was calculated.

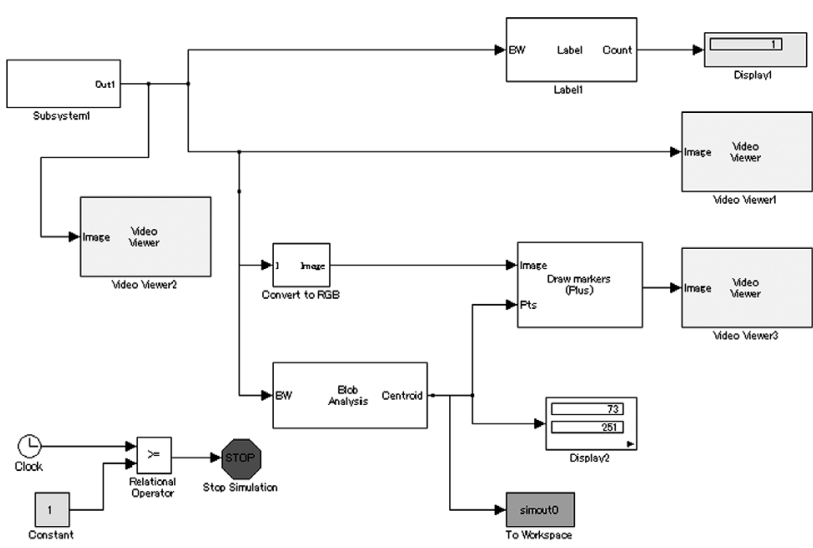

Fig. 3. Simulink model to segmenting one snail and calculating the speed of it from the AVI files of Fig. 2.

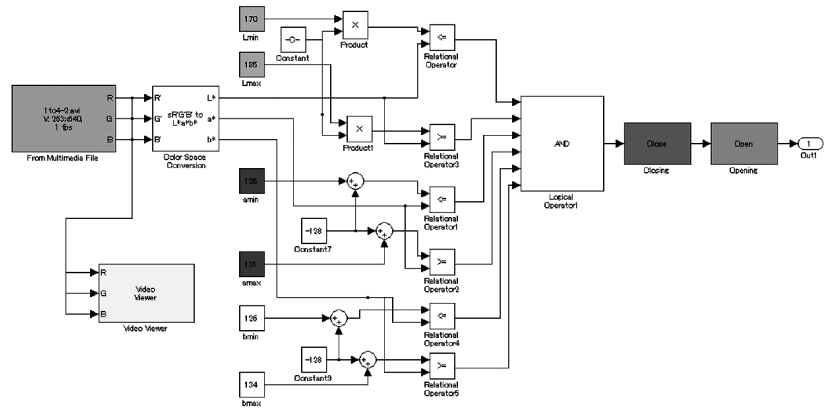

Fig. 4. The subsytem of the Simulink model of Fig. 3.

for labeled regions in a binary image and returns some quantities, such as the centroids, as values that represent spatial coordinate locations (Mathworks, 2008).

Display block connected to the Blob Analysis block in this model. The Draw Markers block can draw multiple circles, $\mathrm{x}$-marks, plus signs, stars, or squares on images by overwriting pixel values. As a result, the shapes are attached on the output image. The symbols of plus sign for representing the coordinates of centroid were set up. Then the coordinates of the centroid of snail of each frame in the AVI file was sent to Matlab workspace through the To Workspace block.

In the case of the movie in the laboratory (Fig. 1) the distance of two centroids with that of the measured in the AVI file were compared and found one pixel corresponds to about $0.43 \mathrm{~mm}$. The video camera of the Field Server was set $1400 \mathrm{~mm}$ above ground and snails were $2450 \mathrm{~mm}$ far from the Field Server. In this case, tilted angle of de camera was 26 degree to the ground. The distance was calculated using equation as follows.

$$
D=\sqrt{((x 2-x 1) * 0.43)^{2}+\left(\frac{\left((y 2-y 1)^{*} 0.43\right)^{2}}{\sin \{\pi(90-\theta) / 180\}}\right)^{2}}
$$

Where

$D=$ traveled distance by the snail in paddy or laboratory $\theta=$ tilt angle of the camera, in this case $26^{\circ}$

$x_{1}$ : abscissa of the centroid 1

$x_{2}:$ abscissa of the centroid 2

$y_{1}$ : ordinate of the centroid 2

$y_{2}:$ ordinate of the centroid 2

For the case of the movie in the paddy (Fig. 2) the target was the snail located in the upper side of two snails in the movie and it was calculated the speed of it. We compared the distance of two centroids with that of the measured in the AVI file and found one pixel corresponds to about $1.43 \mathrm{~mm}$. The video camera of the Field Server tilted with an angle of about 26 degree to the ground. The distance was calculated using the equation 1. After that, the speed of the snail was calculated in each case using the distance calculated by equation 1 and time given by Field Server which recorded the movie. 


\section{RESULTS AND DISCUSSION}

Four frames were obtained with the centroids marked as plus of moving snails from the first AVI file in the laboratory (Fig. 5a) and second AVI files in paddy (Fig. 6). The centroid coordinates of four frames in the first and second AVI files are shown in Fig. $6 \mathrm{~b}$ and Fig. $7 \mathrm{~b}$.

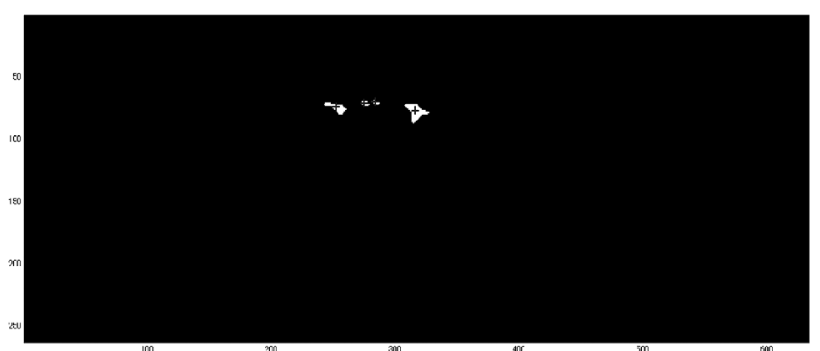

(a)
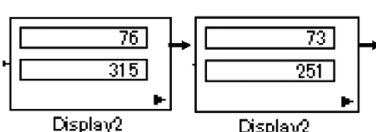

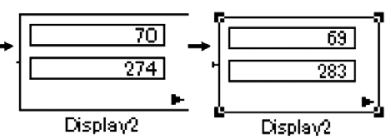

(b)
Fig. 5. Centroid of snails marked by blue plus signs in four frames of the first AVI file of Fig. 1(a) and coordinates of the centroids of the four frames (b).

The coordinates of centroid are automatically exported to the Matlab workspace through the To Workspace block and we can be able to calculate the speed of the snail by via $\mathrm{m}$ file program and export those data to an Excel file.

The data of speed of snail calculated by the Simulink model and the $\mathrm{m}$-files in laboratory and paddy are shown on Table 1 and Table 2 respectively. The speed of the snail depends on the temperature and depth water (Luna et al., 2009d) as well as eating needs by snail.

The actual speed was also compared with the speed of Table 1 which we got from our Simulink model. The actual speed observed was $1.12 \mathrm{~mm} / \mathrm{s}$ and the speed cal-

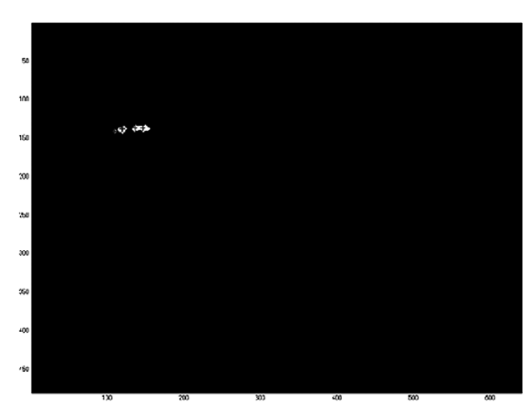

(a)

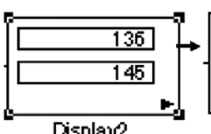

Displav2

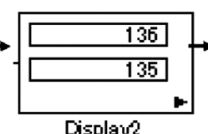

Displav2

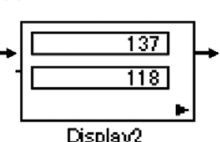

Displave

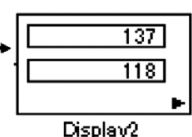

Display2 (b)

Fig. 6. Centroid of snails marked by blues plus signs in four frames of the second created AVI file of Fig. 2(a) and coordinates of the centroids of the four frames (b).
Table 1. Traveled distance and speed of snail in laboratory on tests during 2008

\begin{tabular}{ccc}
\hline $\begin{array}{c}\text { Time interval } \\
(\mathrm{s})\end{array}$ & $\begin{array}{c}\text { Traveled distance } \\
(\mathrm{mm})\end{array}$ & $\begin{array}{c}\text { Speed of snail } \\
(\mathrm{mm} / \mathrm{s})\end{array}$ \\
\hline $0 \sim 5$ & 9.99 & 1.99 \\
$5 \sim 12$ & 3.89 & 0.49 \\
$12 \sim 25$ & 14.1 & 1.18 \\
\hline Total & 27.98 & 1.11 \\
\hline
\end{tabular}

Table 2. Traveled distance and speed of snail in paddy field on crop season of 2008

\begin{tabular}{ccc}
\hline $\begin{array}{c}\text { Time interval } \\
(\mathrm{s})\end{array}$ & $\begin{array}{c}\text { Traveled distance } \\
(\mathrm{mm})\end{array}$ & $\begin{array}{c}\text { Speed } \\
(\mathrm{mm} / \mathrm{s})\end{array}$ \\
\hline $0 \sim 7$ & 14.3 & 2.04 \\
$7 \sim 12$ & 24.3 & 4.87 \\
$12 \sim 19$ & 15.1 & 2.16 \\
\hline Total & 53.7 & 2.83 \\
\hline
\end{tabular}

culated by the model into which the AVI file was imported is $1.11 \mathrm{~mm} / \mathrm{s}$. This suggests that the model of calculation of the speed using image processing is highly consistent with reality.

\section{CONCLUSION}

The speed of snails calculated by our model was found consistent with their real travel speed. Anytime we can calculate the speed of snail through the video camera of the Field Server by using the model we constructed this time and the activity of the snails can be estimated by its travel speed in the paddy using the AVI files image processing. On the other hand, in the future research the parameters of Holling equation (p: predation rate of superior plants by snails and a: predation rate coefficient, which is the search rate or attack efficiency of snails.) could be found using the techniques applied in this paper to know the speed of snail.

\section{REFERENCES}

Deepak Malani D. and A. Malewar, 2008 Introduction to Video analysis using MATLAB, NEX ROBOTICS. (techfest.org/competitions/techtronics/goal/GOAL (Tutorial).pdf ) India, pp. 1-23

MATHWORKS. Video and Image Processing Blockset. User's guide. Matlab and Simulink, USA.

Hwang H., Kim J. H., Choi S, Ho S. and J. Woo Lee 2007 Calibration and grading of beef color via computer vision system. Proceedings of the International Workshop on Agricultural and Biosystems Engineering. Ministry of Education and Training, Nong Lam University, Ho Chi Minh City, Vietnam, pp. 118-126

Luna Maldonado, A. I. and K. Nakaji 2008 Development of an Intelligent Robot for an Agricultural Production EcosystemNew Concept of Robot and Dynamics of a Golden Apple Snail in Paddy-. Journal of the Faculty of Agriculture, Kyushu University, 53: 115-119

Luna Maldonado, A. I., Y. Yamaguchi, M. Tuda and K. Nakaji 2008a Development of an Intelligent Robot for an Agricultural Production Ecosystem (II) - Modeling of the Competition between rice plants and weeds -. Journal of the Faculty of 
Agriculture, Kyushu University, 53: 511-516

Luna Maldonado, A. I., Y. Yamaguchi, M. Tuda and K. Nakaji 2008b Development of an Intelligent Robot for an Agricultural Production Ecosystem (III) - Modeling of the Predation of Rice Plants and Weeds by Golden Apple Snail-. Journal of the Faculty of Agriculture, Kyushu University, 53: 517-521

Luna Maldonado, A. I., Y. Yamaguchi and K. Nakaji 2009c. Development of an Intelligent Robot for an Agricultural Production Ecosystem (IV) - Experiments on Growth and Competition of Rice Plants against Weeds-. Journal of the Faculty of Agriculture, Kyushu University, 54: 231-234

Luna Maldonado, A. I., Y. Yamaguchi and K. Nakaji 2009d. Development of an Intelligent Robot for an Agricultural Production Ecosystem (V) - Experiments on Predation of Paddy by Golden Apple Snails -. Journal of the Faculty of Agriculture, Kyushu University, 54: 235-239

Luna Maldonado, A. I., Y. Yamaguchi and K. Nakaji 2009e.
Development of an Intelligent Robot for an Agricultural Production Ecosystem (VI) - Conbing of Shady in Laboratory and Paddy Field by using Developed Programs of Image Processing.

Mc Andrew A. 2008 An Introduction to Digital Image Processing with Matlab. Notes of SCM2511 Image Processing I. School of Computer Science and Mathematics, Victora University of Technology. (sci.vu.edu.au/ amca/SCM2511/book2511.pdf) Australia, pp. 1-257

Miezianko R. 2008 Creating AVI movie frames in Matlab. Computer and Information Science Department, Temple University. Philadephia, (astro.temple.edu/ rmiezian/pubs/ CreateAVIframesInMatlab.pdf) USA, pp. 1-4

UMASS LOWELL 2006 Importing and exporting data from MATLAB and Simulink to Excel. Dynamic systems. University of Massachusetts Lowell (faculty.uml.edu/.../22.451/Simulink importing_exporting_to_excel.pdf), USA, pp. 1-4 